\title{
CORPOS EM TRÂNSITO E TRAJETÓRIAS TEXTUAIS
}

\section{BODIES IN TRANSIT AND TEXTUAL TRAJECTORIES}

\author{
Joana Plaza Pinto ${ }^{1}$ \\ Daniella do Amaral
}

RESUMO: Este artigo objetiva explorar o entrecruzamento de mobilidade de textos e relatos de mobilidade de corpos, analisando marcas de diferença raciais, nacionais e de gênero na trajetória textual de uma postagem sobre "médicas cubanas" em mídia digital durante os primeiros dias de implementação do Programa Mais Médicos no Brasil, em 2013. Essa trajetória nos permite, por um lado, explorar o potencial explicativo das metáforas de escala e trânsito. Por outro lado, incluímos o debate feminista sobre intersecções e uma releitura feminista linguístico-antropológica dos processos de subjetivação. A análise aponta que as variações de escala se dão tanto no espaço quanto no tempo histórico do racismo brasileiro e que a circulação desses relatos de corpos e dos textos sobre eles aciona tanto sentidos sedimentados, "mulher negra como empregada doméstica", quanto sentidos imprevisíveis, "mulher negra como médicas", sobre o corpo da "mulher negra". Nossas conclusões são: 1) a noção de escala ajuda a pensar os indiciamentos espaciais dentro das configurações históricas coloniais (racismo brasileiro, variação escalar regional nordeste/sudeste, nacional/transnacional); 2) a conexão entre corpos e textos não se limita a religar textos linguísticos, mas redes visuais de corpos e corpos vivos; 3) essas religações promovem ligações de dimensões aparentemente separadas, um multi-indiciamento que suplementa as interações, um deslizamento entre dimensões não estáveis de produções de sentidos.

PALAVRAS-CHAVE: Corpo. Raça. Gênero. Trajetória textual. Programa Mais Médicos.

\begin{abstract}
This article aims to explore the intertwining of the text mobility and the reporting of bodies mobility, analyzing the marks of racial, national and gender differences in the textual trajectory of an online post about "Female Cuban physicians" during the first three days of the implementation program "Mais Médicos" (More Doctors) in Brazil in 2013. On the one hand, this trajectory allows us to explore the explanatory potential of scales and traffic metaphors. On the other hand, we include the feminist debate about intersections and a
\end{abstract}

\footnotetext{
${ }^{1}$ Universidade Federal de Goiás (UFG); joplazapinto@ufg.br
} 
feminist linguistic-anthropological reinterpretation on subjectification processes. The analysis shows that the scale variations take place both in space and in historical time of Brazilian racism and that the circulation of those reports of bodies and texts about them activates both sedimented meanings "black woman as maids", as unpredictable meanings such as "black woman as physician", about the body of the "back woman". Our conclusions are: 1) the notion of scale helps to think the space indictments within the historical colonial configurations (Brazilian racism, regional scalar variation Northeast/Southeast, national/transnational); 2) the connection between bodies and texts is not only about reconnecting linguistics texts, but about reconnecting visual networks of bodies and living bodies; 3) these reconnections promote connections to apparently separated dimensions, to a multi-indictment which supplements the interactions, to a sliding between non-stable meaning production dimensions.

KEY-WORDS: Body. Race. Gender. Text trajectory. Mais Médicos Program. 


\section{CORPOS EM TRÂNSITO E TRAJETÓRIAS TEXTUAIS}

\section{EMBARAÇOS INICIAIS}

Este artigo começou há quase dois anos com uma tentativa de compreender em conjunto a mobilidade de textos e o relato de mobilidade de corpos numa notícia sobre migração qualificada no Brasil $^{2}$. Ambos os assuntos têm sido muito tematizados pela literatura sobre linguagem e globalização, mas pouco pensados em suas relações simultâneas; ou se pensa a mobilidade de textos, ou se pensa o relato sobre ou a própria mobilidade de corpos e pouco se lê sobre como os dois movimentos se articulam ${ }^{3}$. Nos últimos dez anos, a literatura sobre mobilidade de textos cresceu vastamente ${ }^{4}$, tanto em resposta ao desenvolvimento das categorias de análise muito úteis e bem fundamentadas da Linguística Antropológica estadunidense (BAUMAN; BRIGGS, 1990; SILVERSTEIN; URBAN, 1996), quanto em resposta à realidade empírica de textos móveis convertidos em códigos binários nos cabos axiais e satélites mundo afora $^{5}$ (JACQUEMET, 2005; BLOMMAERT, 2010; VARIS, BLOMMAERT, 2015). Nessa mesma literatura, encontramos muitas observações sobre trajetórias dos corpos individuais, especialmente relacionadas às singularidades de

\footnotetext{
${ }^{2}$ A primeira autora apresentou uma versão preliminar desta análise em II Workshop Internacional de Pragmática, na UFPR, Curitiba, PR, Brasil, em 2014.

${ }^{3}$ Bucholtz e Hall [no prelo] confirmam essa omissão da relação entre linguagem e corporalidade nos estudos linguísticos socioculturais, ao mesmo tempo em que convidam a uma mudança para uma "sociolinguística corporificada".

${ }^{4}$ Essa literatura faz uso da noção de trajetória textual para pensar questões de circulação de textos e discursos e de contextos pluri ou multilíngues no mundo contemporâneo. Para citar alguns exemplos recentes: Agha (2003), Blommaert (2008), Blommaert; Rampton (2011), Briggs (2007), Busch (2012), Cody (2009), Fabricio (2015), Heller (2008), Jacquemet (2016), Keating; Solovova (2011), Reyes (2002), Silva (2015), Wortham (2012).

${ }^{5}$ Folcloristas poderiam imaginar em que mundos digitalizados iriam chegar suas categorias de análise construídas sob inspiração de material empírico oral?
} 
percursos sociais de indivíduos em escalas de tempo e espaço, como está explícito em Blommaert (2010) que relaciona a atividade semiótica ao uso do corpo na produção de significados. Em outras obras, o corpo fica implícito sob termos como "indivíduos", "falantes", "sujeito" e correlatos.

Seria possível argumentar que essas noções não têm relação com corpo, mas sim com categorias ontológicas de outra ordem, confirmando o argumento de Grosz (2000) de que "o corpo continua a ser um ponto cego conceitual" no pensamento ocidental. No entanto, para nós, o corpo é parte de uma "rede visual, discursiva, e relações tácitas que se tornam parte da sua historicidade, seu passado, presente e futuro constitutivos" (BUTLER, 2004, p.217). Assim é que o corpo se constitui com noções recebidas da realidade, "relatos implícitos da ontologia" (BUTLER, 2004, p.214), que produzem as versões "verdadeiras" e "reais" do corpo em oposição às versões inexistentes. Usando outro vocabulário, sintetizamos essa articulação entre redes visual, discursiva e tácita e relatos implícitos como uma intersecção metadiscursiva e metapragmática entre corpo e língua, uma sobreposição conceitual que os estudos linguísticos se esforçam em separar, mas que persiste irredutível no corpo falante (BUTLER, 2007). Assim, a diferença como marca social (de gênero, racial, sexual, geopolítica etc.) é a articulação ideológica entre diferença semiótica, linguística e corporal, como mostra Povinelli (2016, p.217), um "espaço colocado pela denotação e pela indexicalidade" que estabelece a categoria social valendo-se da metapragmática.

Diferentemente desta nossa posição, nos trabalhos sobre mobilidade de textos, os corpos parecem ter limites individuais, ainda que certamente inseridos socialmente, e são vistos como aqueles que dominam ou disputam os recursos linguísticos ("idiomas", "variedades", "sistemas de escrita", "gêneros", "estilos", "discursos" etc.) de um local a outro - em fluxo contínuo ou em eventuais estabilizações sedentárias. Os textos são vistos como conjuntos de recursos linguísticos instáveis (BAUMAN; BRIGGS, 1990), enquanto processos de sedimentação e legitimidade em disputa e enquanto produtos (recortados, fragmentados, remontados etc.) em fluxo constante - passados fragmentariamente de boca em boca, de papel em papel, de byte em byte.

Nossas perguntas são: Como corpos e textos se ligam? São os corpos apenas "transportes" para tais recursos? São os corpos apenas mais um objeto no mundo indiciado pela linguagem, seguindo subsumidos ao funcionamento dos recursos linguísticos? Como analisar a articulação simultânea entre textos e corpos no mundo contemporâneo? Que ancoragens corporais e textuais devemos considerar para se pensar que ordens indexicais, que "adequação" e "efetividade" para que relações entre corpos e textos (SILVERSTEIN, 2003)? Dito de outra forma: o que é que o texto faz com o corpo que se faz com o texto?

Para refletir sobre essas perguntas, aspectos diferentes do impacto da noção de mobilidade precisam ser explorados. Primeiro, os corpos falantes, tratados como indivíduos ou como grupo, são sempre corpos em trânsito no tempo e no espaço, e nesse sentido os processos interacionais são dependentes das configurações históricas e ao mesmo tempo contingentes das interações linguísticas. Segundo, os textos produzidos por tais corpos transitam fora do controle intencional do falante (DERRIDA, 1990), por sua vez entre diferentes corpos, seguindo trajetórias que podem projetar sentidos passados e futuros contraditórios e conflitantes. Terceiro, as mobilidades de corpos e textos se sobrepõem em intersecções tanto sedimentadas quanto imprevisíveis, incidindo sobre a (re)configuração de sentidos para os corpos e para os textos.

Nossa proposta neste artigo é explorar o entrecruzamento de mobilidade de corpos e textos, analisando marcas de diferença e hierarquia corporal numa rede discursiva sobre a mobilidade de corpos construída em uma trajetória textual de uma postagem sobre "médicas 
cubanas" durante os primeiros dias de implementação do Programa Mais Médicos no Brasil ${ }^{6}$, em 2013. Esse material empírico ${ }^{7}$ permite, por um lado, explorar o potencial explicativo que metáforas de escala e trânsito apresentam sob as lentes dessa literatura sobre mobilidade. Escala tem sido bastante discutida no campo dos estudos sobre trânsitos textuais. Jacquemet (2016, p.337) sintetiza várias ideias sobre escala na literatura recente ao afirmar que "escalas se referem à ideia de que uma dada atividade humana pode ter diferentes significados quando vistas dentro de contextos de escopo geográfico variado". Voltaremos a essa definição de escala no contexto da análise.

Por outro lado, para continuar explorando as ancoragens interseccionadas entre corpos e textos, limitadas pela sua separação tácita nessa literatura, foi preciso ir um pouco além e encostar na superfície do debate feminista sobre intersecções (BARAD, 2003; BRAH, 2006; BRAH; PHOENIX, 2004; BUCHOLTZ; SKAPOULLI, 2009; MAGLIANO, 2015; PISCITELLI, 2008) e numa releitura linguístico-antropológica dos processos de subjetivação (POVINELLI, 2016). Intersecções, como adotamos aqui, tem a ver com a articulação de categorias de diferença em contexto específico de produção de corpos. Em cada contexto, categorias são articuladas para produzir diferenças. No caso de nossa análise, veremos gênero, raça e nacionalidade como categorias articuladas metapragmaticamente como diferença semiótica e corporal.

\section{O CASO DAS "MÉDICAS CUBANAS COM CARA DE EMPREGADAS DOMÉSTICAS"}

27 de agosto de 2013 foi um dia muito importante para o Programa Mais Médicos. Muitos jornais impressos e digitais noticiaram a chegada de médicos(as) estrangeiros(as) que participariam do Programa. Muitas publicações do dia destacaram o evento e seus desdobramentos para atores sociais diversos. Uma prestigiosa agência de notícias publicou um álbum inteiro de fotografias sobre o lançamento do Programa e as reações públicas de diversos atores sociais. Nesse álbum, uma das imagens era a Figura 1:

\footnotetext{
${ }^{6}$ O Programa Mais Médicos (PMM) caracteriza-se como um programa de incentivo criado pelo Governo Federal brasileiro em julho de 2013, por meio de Medida Provisória, com o intuito de minimizar a escassez de médicos(as) em diversas regiões do país, bem como promover mais investimentos em infraestrutura para a saúde pública e a melhoria do atendimento do SUS (Sistema Único de Saúde). Inicialmente, a proposta era de que as vagas seriam "oferecidas prioritariamente a médicos brasileiros, interessados em atuar nas regiões onde faltam profissionais" (BRASIL, 2013). Somente seriam aceitas candidaturas de estrangeiros(as) caso todas as vagas não fossem preenchidas por médicos(as) brasileiros(as), contudo, uma vez que este era um problema emergencial para o Brasil e as inscrições de médicos(as) brasileiros(as) não foram suficientes para sanar a falta de profissionais, foi feito um pacto entre o governo brasileiro e o governo cubano por meio da OPAS (Organização Pan-Americana da Saúde), bem como foram abertas as inscrições para médicos(as) de quaisquer outras nacionalidades. Em uma primeira avaliação do programa, estimou-se que por meio dessa iniciativa " 14.462 mil médicos passaram a atender a população de 3.785 mil municípios, o equivalente a $68 \%$ dos municípios do país e os 34 Distritos Sanitários Indígenas (DSEIs)" (BRASIL, 2013), o que teria beneficiado cerca de 50 milhões de brasileiros.

${ }^{7}$ Esse material empírico integra o banco de dados de pesquisa coordenada pela primeira autora, que selecionou textos em sites governamentais e sites de mídia diversificada (comercial e não comercial) sobre migrações para o Brasil no período de 2003-2013.
} 
Figura 1 - Notícias UOL, 27 ago. 2013, Seção Saúde Pública

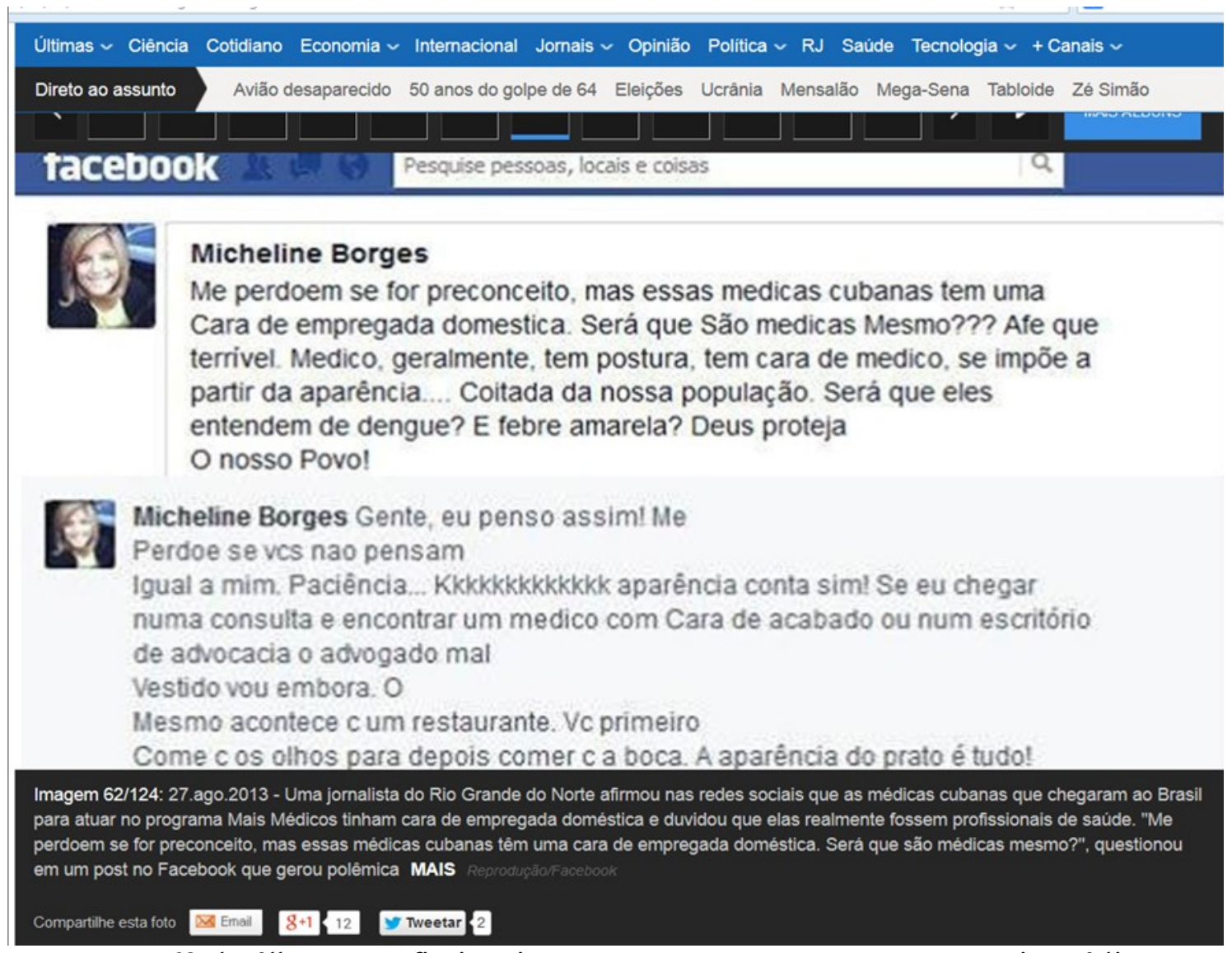

Imagem 62 do álbum "Profissionais começam a atuar no Programa Mais Médicos"

A legenda da Figura 1 noticia "Uma jornalista do Rio Grande do Norte afirmou nas redes sociais que as médicas cubanas que chegaram ao Brasil para atuar no programa Mais Médicos tinham cara de empregada doméstica e duvidou que elas realmente fossem profissionais de saúde". É visível que o Facebook da jornalista foi editado para ser inserido no álbum. Uma separação por cor e marcadores de interação no texto inferior indicam que se trata de uma postagem (fundo branco) e um comentário da jornalista (fundo acinzentado). Além disso, a legenda recorta trechos da postagem tanto sem aspas quanto com aspas. A mudança no tempo verbal na recontextualização do trecho sem aspas "tinham cara de empregada doméstica" funciona como um artifício para afastar o locutor (Notícias UOL) do trecho com aspas "têm uma cara de empregada doméstica".

No mesmo dia, um outro site de notícias recontextualiza a postagem na seção "Educação" (Figura 2) e propõe outra edição da imagem, sem legenda, mas com um título da notícia: "Jornalista se arrepende de comparar médicas cubanas a domésticas". 
Figura 2 - Terra, Seção "Educação”, 27 ago. 2013

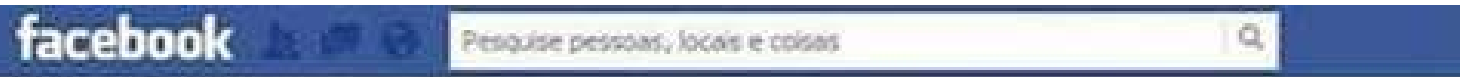

\section{Micheline Borges}

Me perdoem se for preconceito, mas essas medicas cubanas tem uma Cara de empregada domestica. Será que São medicas Mesmo??? Afe que terrivel Medico. geralmente, tem postura, tem cara de medico, se impöe a partir da aparencia. Coltada da nossa população. Será que eles entendem de dengue? E febre amarela? Deus proteja O nosso Povo!

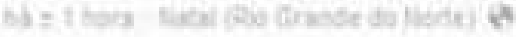

\section{Compartihar}

3 pessoas cuntram isso.

Amanda Sobreira Desde quando apartncia foma ver com competlincia? E cesde quando empregada doméstica tem uma cara? Medico tem cara? Jornalista tem cara? Ta na cara que alguém 6 dombeiro ou tarmaceutco? Aqui no Cears a gente oinana pra o e diria 66

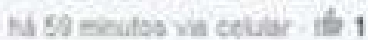

Micheline Borges Entlo, vamos

LS. voce vai trabainar descabelada, de Chinelos esem

Lavar a cara? Vou mais

Adiante: será. Ver mais

nit afr nicuotss vir ceblor - ill 1

Amanda Sobreira Se eu trabalnasse no boticjirio, takez multo talezz eu poderia entender o comentino. Mns to aqui, oe tenis, cara landa, sem escowa ou batom, ralando pra caramoa: E com certeza, ninguem que visse nesse momento, dina que eu sou jornalista.

na se minator vas cellar

Taritza Puggina Desculpa Micheline Borges mas ciscordo veemente da sua colocacto n\$o so quanto aos aspectos físicos das medicas cubanas, mas porque multos midicos brasiloiros que nło conseguiram passar em vestibulares de medieina no brasil cursaram esta faculdade em CUBA e podem multo bem servános dos módicos que nos consuitamos hoje em dia! his 38 moutos va crobur

Mticheline Borges É 6 Amanda, doura de ser zanha. Nao To agui pra polemicar com ninguim, apenas expressando um pensamento que pode pu nao ser parthado Cada um

Pensa do jelto que acha correto, O legal desso tudo \&a gente conseguir etrair o Iado bem Respeits ao pensamento do prdximo 6 o primeiro passo . Nias, 9 Mundo só \& marawhos graça a essa missigenacao de idbias e pensamentos.

hat minctas vis cetiay

Outro site de notícias, mais um no mesmo dia, recontextualiza o texto e comentários do Facebook. O título da notícia é "Jornalista diz que médicas cubanas parecem 'empregadas domésticas", o lide é “"Será que são médicas mesmo?', questiona Micheline Borges no Facebook. Após mais de 5 mil compartilhamentos, ela excluiu a conta na rede social" e a legenda da imagem "Mensagem gerou polêmica nas redes sociais nesta terça". A estratégia de 
mudança verbal - nesse caso, a expressão "têm cara" é substituída por "parecem" - é acompanhada do local da notícia, neste veículo na "Regional $\mathrm{RN}$ ", sendo $\mathrm{RN}$ a sigla do estado em que mora a autora da postagem.

Figura 3 - G1, 27 ago. 2013, Seção: Regional RN

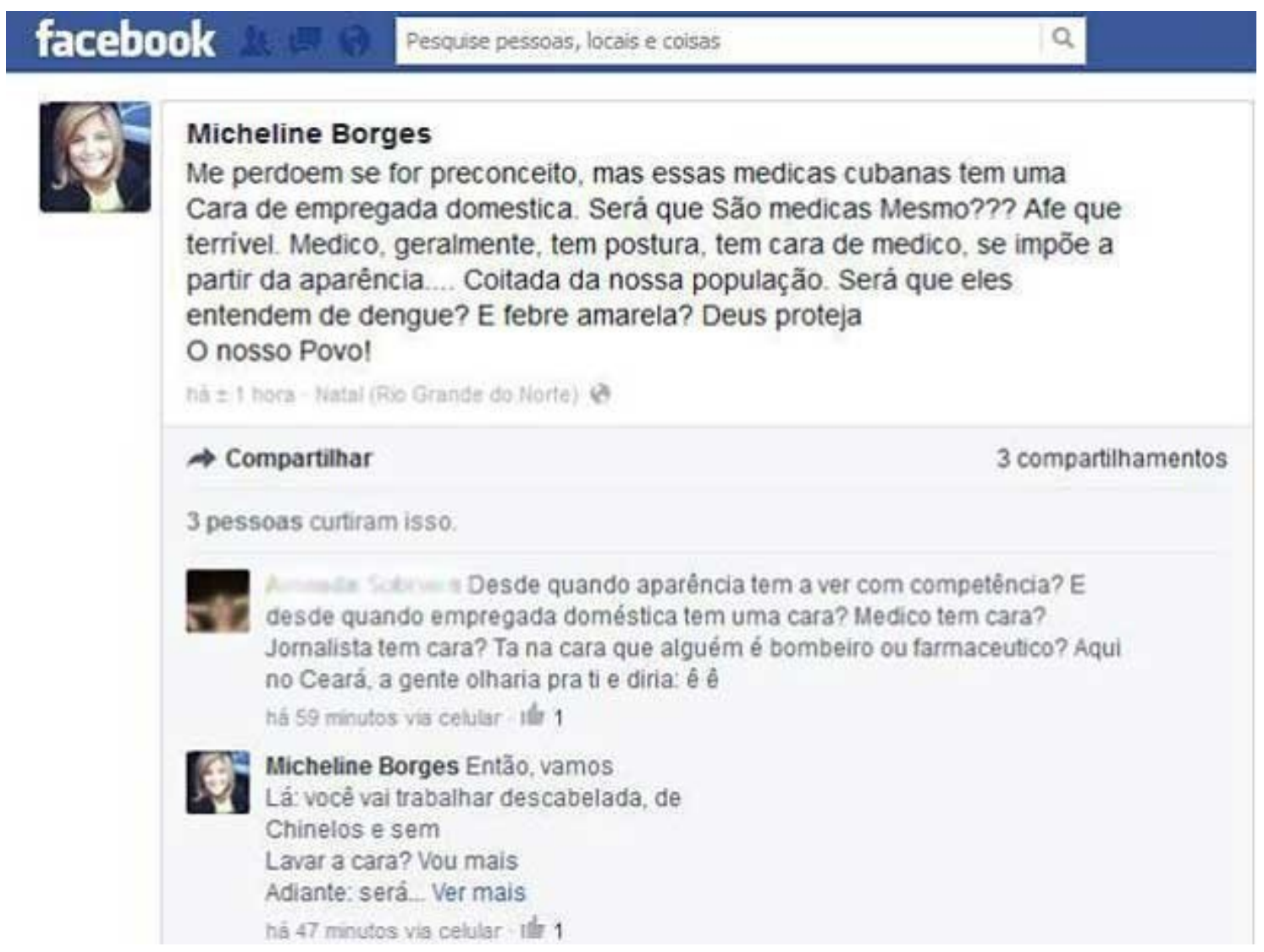

Essa escolha de escala espacial vertical recebe uma designação no jargão profissional de jornalistas: "enterrar a notícia". Enquanto a seção Saúde coloca a notícia no seu campo temático mais óbvio e em escala nacional, a seção Educação, ainda que em escala nacional, esconde a notícia do seu campo temático mais óbvio (Saúde), e a seção regional "enterra a notícia" de escopo nacional no regional. Ao mesmo tempo, as diferentes estratégias de entextualização atribuem diferentes forças ao sentido "escandaloso" do evento: quanto mais local a escala da seção em que se localiza a notícia, mais a jornalista tem espaço de resposta e sua voz, central nas entextualizações diretas (sem aspas), tem direito a novas citações com aspas. Essas mesmas estratégias de entextualização encontradas nos títulos, legendas ou lides das notícias, estão presentes nos textos completos das notícias. O adjetivo "mal-interpretado" é usado nas notícias das Figuras 2 e 3 para designar a jornalista ou seus comentários e suas desculpas são extensas conforme a escala da notícia, chegando à mais local: "[...] as pessoas interpretam do jeito que querem. Não tenho preconceito com ninguém, não quis atingir ninguém, nem ferir a imagem nem a profissão de ninguém".

Essas estratégias escalares de entextualização para "enterrar a notícia" se combinam com inserções de vozes contrárias em nível regional, recombinando estratégias de "neutralidade" com as de "enterrar notícia". Assim, o "Sindicato das Empregadas Domésticas do Rio Grande do Norte" é o único ator com direito à voz (numa das notícias) que cita a palavra "racismo". Não se leem vozes das médicas cubanas. 
Como textos seguem sem o controle intencional dos(as) usuários(as), a notícia não é enterrada orquestradamente, muito menos definitivamente, sendo que as variações de escala não seguem uma ordem cronológica. Tanto que no dia seguinte, um portal de notícias de um grupo de feministas negras postou uma coluna recontextualizando a postagem. Usando uma imagem associada a textos sobre elogios públicos estadunidenses aos(às) médicos(as) cubanos(as) envolvidos(as) no combate ao Ebola em África (Figura 4), a coluna assinada por Marcos Romão, cujo título é "Negras médicas e domésticas", articula diferenciações corporais (especialmente raciais, mas também nacionais e de gênero), escala espaciais e também históricas na recontextualização da postagem da jornalista. Primeiro, a racialização atual e histórica das profissões no Brasil, como no trecho sobre a racialização atual das profissões: "Aqui não, se é branco é alguém, se não é branco que nos convença. Aqui no Brasil se tem cara e não se tem cara e a cor da cara ajuda a definir a profissão, a posição e o poder diagnosticado na pessoa que você se confronta [...] Aqui a cara define a sua profissão, o seu poder e a sua preferência no trânsito da vida profissional", e num trecho sobre racialização histórica: "Foi chocante assistir a chegada dos médicos cubanos em São Paulo [...] um monte de mulheres e homens com as caras dos peixeiros de nossas esquinas, fortes como os entregadores de gás do dia a dia, e com aquele olhar afável das nossas queridas empregadas domésticas, isto não estava no meu enredo de vida como um brasileiro negro, pois eram e são todas e todos médicas e médicos."

Segundo, o deslizamento entre escala e racialização, como no trecho "Assim quando a jornalista potiguar, cor de 'barata sem casca". Terceiro, a "cordialidade racial" e o tabu do racismo na história do Brasil, como no trecho "Quase sempre tem dado certo prá todo mundo. Quando não dá certo e alguém grita racismo, vem logo a desculpa, mas foi um mal entendido, esta não foi a nossa intenção".

Figura 4 - Primeira imagem na coluna de Marcos Romão, 28/08/2013, Portal Geledés

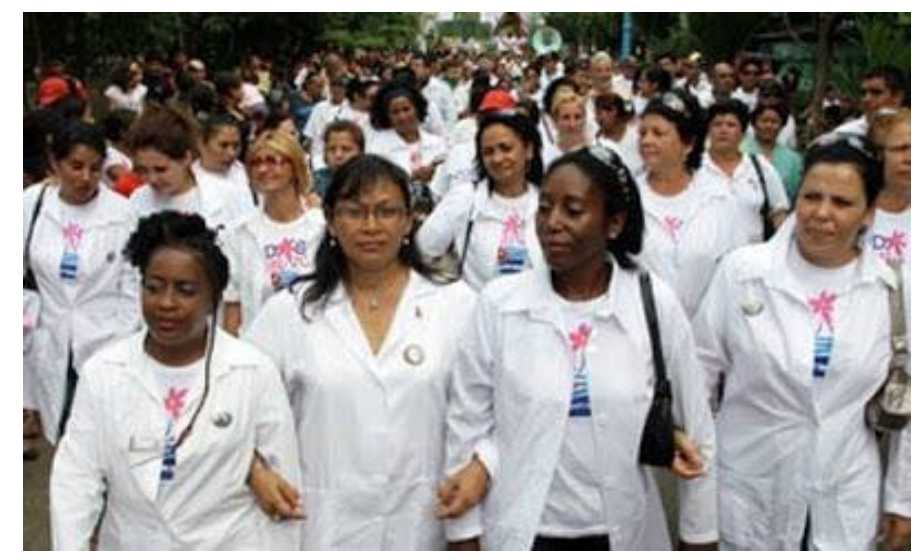

Um outro blog movimenta mais uma vez a escala espacial e adiciona um elemento para essa análise ao incluir a questão do embranquecimento, política racial pós-colonial - um tempo intermediário entre a história do racismo colonial e os racismos contemporâneos. $\mathrm{O}$ blogueiro Igor Santos publica uma coluna (SCIENCEBLOG.42, de IGOR SANTOS, 29/08/2013) intitulada "Mas médicas cubanas têm sim cara de empregada doméstica!" e uma foto da jornalista ${ }^{8}$ com a legenda "A 'branca' jornalista Micheline Borges. Foto retirada de seu perfil público do Facebook, via Google Cache". Primeiro, o blogueiro aciona as escalas regional, nacional e transnacional no mesmo texto, em denotativos e dêiticos de escala

\footnotetext{
${ }^{8}$ Como se trata de uma foto em que a jornalista aparece com uma criança, consideramos melhor não inclui-la aqui.
} 
regional em "Anteontem, uma jornalista da minha terra [...]" e de escalas transnacional e nacional em "As cubanas são marrons. E as marrons brasileiras são, via de regra, pobres" ou "Como Cuba tem educação para todo mundo, às vezes até forçada, até quem é marrom pode virar médica. Lá. Aqui não. Aqui as marrons precisam ganhar dinheiro limpando 'casa de família"'. A escala vertical é perturbada, não apenas pela coexistência de escalas regional (Rio Grande do Norte), nacional (Brasil) e transnacional (Brasil-Cuba), mas por importantes trânsitos de escala histórica (racismo colonial, tabu do racismo, história racializada e de gênero das profissões).

Como mencionamos no início, uma parte da literatura sobre escala adota apenas sua metáfora geopolítica e ignora a potencialidade da escala histórica - essa potencialidade tem sido reconhecida em outros trabalhos (BLOMMAERT, 2010; WORTHAM, 2012; SCHILLER, 2012). Esse potencial da articulação tempo e espaço na metáfora de escala é importante pelo fato de que a variação dos significados de uma atividade comunicativa não é um coeficiente do contexto (seja geográfico ou temporal) porque as possibilidades indexicais de um dado texto estão disponíveis sempre ao mesmo tempo, deslizando dos contextos normativos mais vigiados aos contextos imprevistos menos regrados. Como explica Silverstein (2003), as esquematizações normativas de um contexto particular se combinam ao mesmo tempo com os encadeamentos "criativos", e parecem mesmo depender disso para funcionar, enquanto seus usos se constituem em relação direta com o grau de engajamento ideológico dos(as) usuários(as) em relação aos significados das esquematizações em jogo.

Essa problemática nas mobilidades implícitas na noção de escala se complicam um pouco mais diante do fato de que todas as notícias - e mais colunas, comentários e matérias de revistas posteriores - dependem das redes visuais indiciadas em "médicas", "médicas cubanas", "empregadas domésticas", corpos de "mulheres negras" conectadas por sua historicidade colonial, pós-colonial e sua presença contemporânea. Como afirma Butler (2004, p.217):

\footnotetext{
Corpos não são habitados como espaços vazios. Eles estão, na sua espacialidade, também em andamento no tempo: agindo, alterando a forma, alterando o significado - dependendo das suas interações - e a rede visual, discursiva, e relações tácitas que se tornam parte da sua historicidade, seu passado, presente e futuro constitutivos.
}

Em certa medida, tal historicidade são ordenações indexicais condensadas num painel caleidoscópico em diferensa (DERRIDA, 1990). Para sintetizar com muitos riscos, diferensa pode ser substituída por diferir, adiar o sentido único e literal, acionando os três sentidos dicionarizados para "diferir" ao mesmo tempo - distinguir-se, divergir e adiar. Assim, adiada no texto escrito, divergida nos corpos relatados em imagens, a simultaneidade escalar dessa trajetória textual coloca em movimento a desconstrução, não apenas da noção de escala, mas principalmente da possibilidade analítica de textos sem corpos.

\section{QUE MARCAS PARA QUE CORPOS?}

Barad (2003, p.23) argumenta que "corpos não são objetos com fronteiras e propriedades inerentes, são um fenômeno discursivo-material". Essa visão pós-humanista de corpos coaduna com a nossa preocupação com a articulação simultânea de corpos e textos nas análises sobre mobilidades. A intersecção de marcas de diferença são necessariamente posicionalidades móveis (BUCHOLTZ; SKAPOULLI, 2009) e seu uso analítico parece ajudar a evitar universalismos e classificações sociais estáveis. Mas como podemos analisar essas marcas sem cair em afirmações universais sobre os corpos (evidentemente racializados?) ou 
deixar apagar as marcas? A resposta nos chega pela articulação entre uma certa concepção da linguagem em uso e uma certa concepção de subjetivação.

Há mais de trinta anos, Silverstein (1979) afirmou que não existe fora do uso linguístico qualquer domínio semiótico do sentido, da significação de uma palavra ou da expressão que emana da organização formal e da sistemática gramatical. O uso linguístico compreende o domínio semiótico da indexicalidade da significação e a indexicalidade tem a ver com as dinâmicas de como as formas linguísticas do "agora-dito remontam ao e de alguma forma incorporam ou ressoam o já-dito e chegam à frente, antecipam, e de alguma forma incorporam o a-ser-dito" (BAUMAN, 2005, p.145).

Mas o uso linguístico não se limita às ligações entre formas linguísticas e contextos. Para funcionar, o uso linguístico precisa daquilo que Silverstein nomeou como metapragmáticas. As metapragmáticas, inseridas num contexto histórico e numa vida social, são conectadas a vários sistemas hierárquicos, na medida em que indiciam diferenças e desigualdades e orientam as ligações entre textos, cotextos e contextos (BAUMAN; BRIGGS, 1990; SILVERSTEIN; URBAN, 1996). Ao mesmo tempo, metapragmáticas são centrais na construção dinâmica relacional da diferença e da produção de subjetividades.

Povinelli (2016) também distingue um aspecto central nessa articulação, que gostaríamos aqui de enfatizar para entender melhor o lugar do corpo nessa pequena trajetória da notícia sob análise. Assim como a socialização da linguagem fornece os meios pragmáticos e metapragmáticos para ligações coerentes entre textos e corpos, também oferece estruturas que possibilitam colocar em questão as próprias normas de socialização. $\mathrm{O}$ exemplo mais evidente de Povinelli (2016) é a condicional, aprendida tanto em socializações normativas quanto em ressignificações muito eficientes, como "Ela pode ser uma mulher".

As estruturas e funções pragmáticas e metapragmáticas, assim como as instituições, espaços e agentes mediadores dessa socialização pela linguagem, no nosso caso a mídia digitalizada, ordenam os contextos pressupostos pelo já-dito e as consequências implicadas por um a-dizer da maneira apropriada de ser um sujeito corporificado (no nosso caso, num gênero, numa raça, numa nacionalidade). Os recursos linguísticos como parte da historicidade dos corpos, seu passado, presente e futuro colonial, nacional, racial, de gênero, integram, rearticulam e criam interligações com os sistemas de diferenciações dos corpos.

Assim, no material empírico aqui analisado, marcas de diferença (gênero, raça, nacionalidade) transitam entre configurações históricas coloniais (racismo brasileiro, variação escalar regional nordeste/sudeste, nacional/transnacional) e interações contingentes da América Latina contemporânea (médicos cubanos no PMM, migrações qualificadas, racializações diversificadas latinamericanas) num fluxo que coloca em disputa os sentidos dessas diferenças. Ao mesmo tempo, a trajetória de textos produzidos por/sobre corpos diferenciados por gênero e raça projetam diferentes significados para as disputas de sentidos sobre o que seria um corpo de "mulher negra" (empregada doméstica? médica? jornalista "embranquecida"?).

Por fim, a circulação desses corpos marcados e dos textos sobre eles/deles aciona tanto sentidos sedimentados ("cara de empregada doméstica") quanto sentidos imprevisíveis ("médica negra") sobre "a mulher negra na sociedade brasileira".

A pressuposição do contexto e aquilo que decorre dela é a propriedade da indexicalidade que entra em jogo para dar, se assim se pode dizer, um tipo de bússola, uma orientação de continuidade no espaço-tempo, religando as situações, as frases, os textos e as interlocuções face a face. (POVINELLI, 2016, p.210-211)

Essa bússola não se limita a religar textos linguísticos, mas imagens de corpos e corpos vivos, promovendo ligações de dimensões aparentemente separadas, trânsitos entre 
textos, imagens e corpos, trânsitos entre o pragmático, o metapragmático e o corpo-nomundo, trânsitos entre indiciamentos de níveis diversos. Essa espécie invisível de multiindiciamento é uma diferensa, um suplemento das interações, um deslizamento entre dimensões não estáveis de produções de sentidos. É nessa diferensa que o tempo longo da história se conecta com o presente mais imediato dos textos, evocando formas, situações e corpos numa mesma condensação de sedimentos passados. Essa condensação não faz outra coisa senão projetar um futuro para os usos dos textos e das práticas permitidas ou obrigadas a corpos relatados em tais textos. Essa relação nem sempre é evidente e raramente se estabiliza, ainda mais quando se trata de disputar as ligações possíveis para textos em circulação pública.

Estudar as redes visuais coloca em destaque o problema da fixidez, dos estereótipos, a violência discursiva como impossibilidade de falar por si, ao mesmo tempo em que coloca em evidência também um grupo de recursos subjetivantes, ou seja, recursos que participam das construções de discursos em processos de subjetivação. Quando temos textos estáticos e fixados num suporte como corpus de análise, ficamos tentadas a ver a fixidez tanto nos produtos (textos) quanto nos processos (discursos). Apesar da crítica de Barad (2003) às concepções limitantes de corpo, aqui concluímos a urgência das interações entre esses textos, esses corpos-representados e corpos-falantes-vivos. O movimento em direção a migrantes racializadas e generificadas no contexto contemporâneo brasileiro - nos encontrarmos, conversarmos com elas e as ouvirmos - é a única saída para avançar as ideias sobre o que é que o texto faz com o corpo que se faz com o texto.

\section{REFERÊNCIAS}

AGHA, Asif. The social life of cultural value. Language \& Communication, v.23, p.231$273,2003$.

BARAD, Karen. Posthumanist Performativity: Toward an Understanding of How Matter Comes to Matter. Signs, v.28, n.3, p.801-831, 2003.

BAUMAN, Richard. Commentary: Indirect Indexicality, Identity, Performance: Dialogic Observations. Journal of Linguistic Anthropology, v.15, n.1, p.145-150, 2005.

BAUMAN, Richard; BRIGGS, Charles L. Poetics and performance as critical perspectives on language and social life. Annual Reviews of Anthropology, v.19, p.59-88, 1990.

BLOMMAERT, Jan. Contexto é/como crítica. In: SIGNORINI, Inês (org.). Situar a linguagem. São Paulo: Parábola, 2008. p.91-115.

BLOMMAERT, Jan. The sociolinguistics of globalization. Cambridge: University Press, 2010.

BLOMMAERT, Jan; RAMPTON, Ben. Language and superdiversity. Diversities, v.13, n.2, p.1-22, 2011.

BRAH, Avtar. Diferença, diversidade, diferenciação. Cadernos Pagu, Campinas, n.26, p.329-376, 2006.

BRAH, Avtar; PHOENIX, Ann. Ain't I a Woman? Revisiting Intersectionality. Journal of International Women's Studies, v.5, n.3, P.75-86, 2004. 
BRASIL. Ministério da Saúde. Mais Médicos para o Brasil. Mais saúde para você. 2013. Disponível em: < http://portalsaude.saude.gov.br/index.php/cidadao/acoes-e-programas/maismedicos/mais-sobre-mais-medicos/5953-como-funciona-o-programa > Acesso em: 11 mar. 2014.

BRIGGS, Charles L. Anthropology, Interviewing, and Communicability in Contemporary Society. Current Anthropology, v.48, n.4, p.551-580, ago. 2007.

BUCHOLTZ, Mary; HALL, Kira. [no prelo] Embodied Sociolinguistics. In: COUPLAND, N. (Ed.). Sociolinguistics: Theoretical Debates. Cambridge: University Press.

BUCHOLTZ, Mary; SKAPOULLI, Elena. Youth language at the intersection: from migration to globalization. Pragmatics, v.19, n.1, p.1-16, 2009.

BUSCH. Brigitta. The Linguistic Repertoire Revisited. Applied Linguistics, v.33, n.5, p.503523, 2012.

BUTLER, Judith. Excitable speech: the politics of performative. New York: Routledge, 2007.

BUTLER, Judith. Undoing gender. New York: Routledge, 2004.

CODY, Francis. Daily Wires and Daily Blossoms: Cultivating Regimes of Circulation in Tamil India's Newspaper Revolution. Journal of Linguistic Anthropology, v.19, n.2, p.286309, 2009.

DERRIDA, Jacques. Limited Inc. Paris, Galilée, 1990.

FABRICIO, Branca F. Infectious repetition-differentiation in an on-line debate on sexualities: Textual friction, scale shifts and resemiotization potential. Working Papers in Urban Language \& Literacies, n.167, p.1-17, 2015.

GROSZ, Elizabeth. Corpos reconfigurados. Cadernos Pagu, n.14, p.45-86, 2000.

HELLER, Monica. Language and the nation-state: Challenges to sociolinguistic theory and practice. Journal of Sociolinguistics, v.12, n.4, p.504-524, 2008.

JACQUEMET, Marco. Language in the Age of Globalization. In: BONVILLAIN, Nancy. (ed.). The Routledge Handbook of Linguistic Anthropology. London: Routledge, 2016. p.329-347.

JACQUEMET, M. Transidiomatic practices: Language and power in the age of globalization. Language \& Communication, v.25, 2005, p.257-277.

KEATING, Maria Clara; SOLOVOVA, Olga. Multilingual dynamics among Portuguesebased migrant contexts in Europe. Journal of Pragmatics, v.43, p.1251-1263, 2011.

MAGLIANO, María José. Interseccionalidad y migraciones: potencialidades y desafíos. Estudos Feministas, Florianópolis, v.23, n.3, p.691-712, dez. 2015. 
PISCITELLI, Adriana. Interseccionalidades, categorias de articulação e experiências de Migrantes brasileiras. Sociedade e Cultura, v.11, n.2, p.263-274, jul. 2008.

POVINELLI, Elizabeth. Pragmáticas íntimas: linguagem, subjetividade e gênero. Trad.: Joana Plaza Pinto. Estudos Feministas, Florianópolis, v.24, n.1, p.205-237, abr. 2016.

REYES, Angela. “Are you losing your culture?": poetics, indexicality and Asian American identity. Discourse Studies, v.4, n.2, p.183-199, 2002.

SCHILLER, Nina Glick. Transnationality, Migrants and Cities: A Comparative Approach. In: AMELINA, N. et al. Beyond Methodological Nationalism: Research Methodologies for Cross-Border Studies. New York: Routledge, 2012. p.23-40.

SILVA, Daniel N. Introduction: The pragmatics of discourse circulation. Pragmatics \& Society, v.6, p.161-174, 2015.

SILVERSTEIN, Michael. Indexical order and the dialectics of sociolinguistic life. Language \& Communication, v.23, p.193-229, 2003.

SILVERSTEIN, Michael. Language Structure and Linguistic Ideology. In: CLYNE, Paul et al. The Elements. Chicago: University of Chicago, 1979. p.193-247.

SILVERSTEIN, Michael; URBAN, Greg. (ed.). Natural Histories of Discourse. Chicago: The University of Chicago Press, 1996.

VARIS, Piia; BLOMMAERT, Jan. Conviviality and collectives on social media: Virality, memes, and new social structures. Multilingual Margins, v.2, n.1, p.31-45, ago. 2015.

WORTHAM, Stanton. Introduction to the Special Issue: Beyond Macro and Micro in the Linguistic Anthropology of Education. Anthropology \& Education Quarterly, v.43, n.2, p.128-137, 2012. 